\title{
Sesame fractions and lipid profiles: a systematic review and meta-analysis of controlled trials
}

\author{
Saman Khalesi ${ }^{1}$, Ernesta Paukste ${ }^{1}$, Elham Nikbakht ${ }^{2}$ and Hossein Khosravi-Boroujeni ${ }^{1 *}$ \\ ${ }^{1}$ Population and Social Health Research Program, School of Medicine, Menzies Health Institute Queensland, Griffith \\ University, Gold Coast, QLD 4222, Australia \\ ${ }^{2}$ Molecular Basis of Disease Program, School of Medical Science, Menzies Health Institute Queensland, Griffith University, Gold \\ Coast, QLD 4222, Australia
}

(Submitted 30 June 2015 - Final revision received 28 October 2015 - Accepted 11 November 2015 - First published online 13 January 2016)

\section{Abstract}

Increased plasma lipid profiles are among the most important risk factors of CHD and stroke. Sesame contains considerable amounts of vitamin E, MUFA, fibre and lignans, which are thought to be associated with its plasma lipid-lowering properties. This study aimed to systematically review the evidence and identify the effects of sesame consumption on blood lipid profiles using a meta-analysis of controlled trials. PubMed, CINAHL and Cochrane Library databases were searched (from 1960 to May 2015). A total of ten controlled trials were identified based on the eligibility criteria. Both the Cochrane Collaboration tool and the Rosendal scale were used to assess the risk of bias of the included studies. The meta-analysis results showed that consumption of sesame did not significantly change the concentrations of total blood cholesterol $\left(-0.32 \mathrm{mmol} / \mathrm{l} ; 95 \% \mathrm{CI}-0 \cdot 75,0 \cdot 11 ; P=0 \cdot 14, I^{2}=96 \%\right)$, LDL-cholesterol $(-0 \cdot 15 \mathrm{mmol} / \mathrm{l} ; 95 \%$ CI $\left.-0.50,0.19 ; P=0.39, I^{2}=96 \%\right)$ or HDL-cholesterol $\left(0.01 \mathrm{mmol} / 1 ; 95 \% \mathrm{CI}-0 \cdot 00,0 \cdot 02 ; P=0 \cdot 16, I^{2}=0 \%\right)$. However, a significant reduction was observed in serum TAG levels $\left(-0.24 \mathrm{mmol} / \mathrm{l} ; 95 \% \mathrm{CI}-0.32,-0 \cdot 15 ; P<0.001, I^{2}=84 \%\right)$ after consumption of sesame. It was concluded that sesame consumption can significantly reduce blood TAG levels but there is insufficient evidence to support its hypocholesterolaemic effects. Further studies are required to determine the potential effect of sesame consumption on lipid profiles and cardiovascular risk factors.

\section{Key words: Sesame: CHD: TAG: Cholesterol: LDL-cholesterol: HDL-cholesterol}

CHD is one of the major causes of death worldwide ${ }^{(1)}$. Increased plasma cholesterol levels and LDL-cholesterol concentrations are among the most important risk factors of CHD and stroke ${ }^{(2)}$. Oxidation of LDL-cholesterol triggers the generation of a series of oxidative reactions, promoting the initiation of atherosclerosis ${ }^{(3)}$. The literature indicates that antioxidants and oils rich in PUFA and MUFA, such as sesame oil, have cardiovascular protective characteristics ${ }^{(4)}$. Antioxidants (such as vitamin E) are known to protect LDL-cholesterol against oxidative modification ${ }^{(5,6)}$. In addition, the consumption of PUFA- and MUFA-rich oils may help decrease the fractions of circulating lipid levels, as well as the risk of $\mathrm{CHD}^{(7,8)}$.

For thousands of years, sesame has been used as an important ingredient in cooking worldwide, especially in Asian countries. However, only recently it has attracted research attention for its medicinal properties and physiological effects $^{(9)}$. Sesame oil contains considerable amounts of vitamin E ( $40 \mathrm{mg} / 100 \mathrm{~g}$ oil), PUFA ( $43 \%$ of oil) and MUFA ( $40 \%$ of oil $)^{(10)}$. The seeds also contain sesame lignans including sesamin, episesamin and sesamolin, which are effective antioxidants $^{(11,12)}$ (mean amount of lignans in sesame oil is
$11.51 \mathrm{mg} / \mathrm{g}^{(13)}$ and $5.81 \mathrm{mg} / \mathrm{g}$ in sesame seeds $\left.{ }^{(14)}\right)$. High amounts of $\alpha$-tocopherol and lignans in sesame oil underlie its capacity as a naturally stable edible oil with strong radicalscavenging properties ${ }^{(15)}$. Further, high linoleic acid and dietary fibre contents of sesame seed may be responsible for its plasma cholesterol-lowering properties ${ }^{(16)}$. Studies conducted on the biological activities of sesamin have shown its effects on the following: the inhibition of lipid metabolism; intestinal cholesterol absorption; desaturation in PUFA biosynthesis; and the inhibition of the activity of acyl-CoA reductase ${ }^{(17)}$. Several animal studies have also confirmed that the intake of sesame seeds or sesamin has cholesterol-lowering effects ${ }^{(18,19)}$. The literature also reports that sesame lignans improve lipid profiles, lipid peroxidation, serum lipoprotein metabolism, increase apoA and decrease atherogenic apoB ${ }^{(19-22)}$. However, in human studies, the evidence of the effects of sesame or sesame oil on lipid profiles and cardiovascular risk factors is inconsistent ${ }^{(10,23-25)}$. Therefore, this systematic review and meta-analysis of randomised clinical trials was conducted to summarise the available evidence and to increase statistical ability in order to detect the effect of sesame consumption on lipid profiles in humans. 


\section{Methods}

\section{Literature search}

Two researchers searched online databases including PubMed (MEDLINE), CINAHL and Cochrane Library (Central) to identify potentially relevant studies that evaluated the effects of sesame on lipid profile, dating from 1960 to May 2015. The following terms (including $\mathrm{MeSH}$ terms) and their combinations were used to search for publications: sesame, sesamin, sesamum, lipid, cholesterol, chol, triglyceride, TG, lipoprotein, LDL, LDL-C, HDL and HDL-C. Two researchers independently screened the titles, abstracts and full texts of the identified articles and made decisions regarding inclusion or exclusion of the articles. A third researcher was involved in the decision-making process in case of disagreement. Selection of studies was based on predetermined inclusion and exclusion criteria. Studies were included if they (1) were randomised or non-randomised controlled trials, (2) included adults ( $\geq 18$ years of age) in their intervention, (3) used sesame seed or its extract (such as oil and powder) and (4) had accessible full-text articles in English. Studies using sesame (or its extracts) in combination with other dietary components (e.g. mixture of sesame oil and fish oil) were included if the other component could be controlled. Studies were excluded if the duration of sesame consumption was $<2$ weeks or the dose of sesame (or its extracts) consumption was not reported.

In screening the literature and presenting results, the 'Preferred reporting items for systematic reviews and meta-analysis: the PRISMA statement' was followed ${ }^{(26)}$. A summary of the review and the reasons for excluding studies are presented in the PRISMA flow chart (see Fig. 1). This systematic review is registered at the International Prospective Register for Systematic Review with the registration number CRD42014013244.

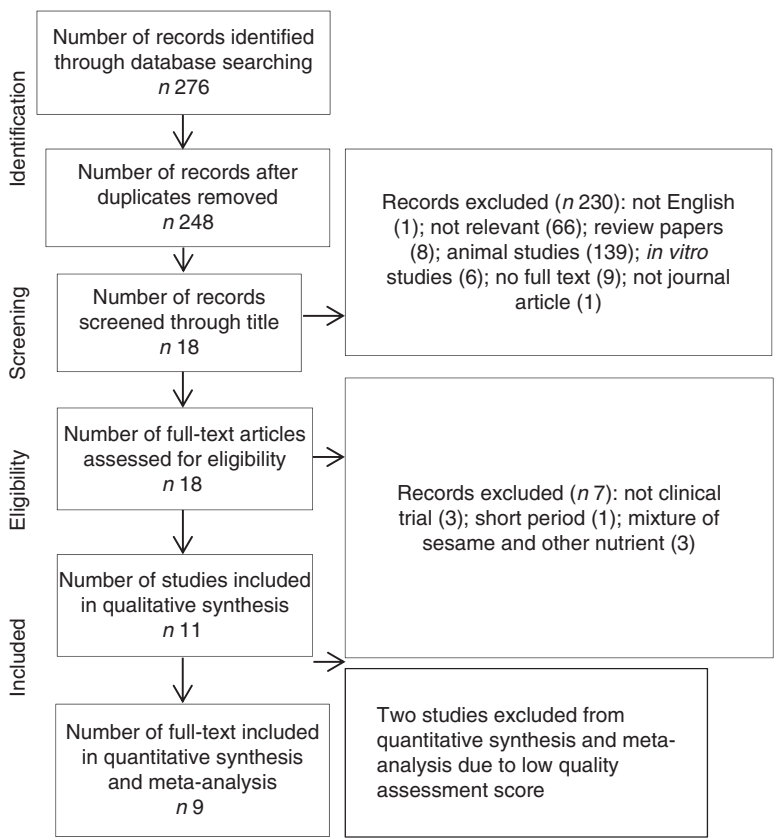

Fig. 1. Preferred reporting items for systematic reviews and meta-analysis flow chart.

\section{Quality assessment and data extraction}

The Cochrane Collaboration tool and the Rosendal scale ${ }^{(27)}$ were used to assess risk of bias and the methodology quality of the included studies. Studies that scored $60 \%$ or more, based on the Rosendal scale, were classified as excellent methodological quality studies $^{(27)}$. A Rosendal score of $<50 \%$ was chosen as the cut-off point for the exclusion of studies. Studies were also excluded if they were ranked as high risk of bias based on the Cochrane quality assessment tool. To extract relevant data from the included studies, the 'Checklist of items to consider in data collection' from the Cochrane Handbook for Systematic Review of Interventions ${ }^{(28)}$ was followed. In the process of data collection, the following information was extracted from each study: study design, location, characteristics of the participants, intervention/control characteristics (supplementation, duration and dose), baseline and final measures, body weight changes, dietary measures and side-effects.

\section{Data synthesis and analysis}

RevMan software (Cochrane Review Manager version 5.2) was used to perform meta-analysis of the data. The mean difference of changes between the intervention groups and control groups was defined as the effect of nutrition intervention. Statistical analysis was performed following the Cochrane Handbook for Systematic Review of Interventions ${ }^{(28)}$ guidelines. A correlation coefficient $(r)$ of 0.5 was chosen to impute the standard deviation of change for all interventions ${ }^{(28)}$. Considering differences in the design of included studies, the DerSimonian \& Laird $^{(29)}$ random effect model was selected to perform the metaanalysis. The $I^{2}$ index was evaluated to assess heterogeneity. Low, moderate and high heterogeneity were defined as $I^{2}$ index equal to 25,50 and $75 \%$, respectively ${ }^{(28)}$. Statistically significant difference was defined as an effect with a $P$ value of $<0 \cdot 05$.

\section{Sensitivity and subgroup analysis}

A one-by-one sensitivity analysis was performed to assess the effect of individual studies on the overall meta-analysis results. The robustness of the meta-analysis was assessed using alternative correlation coefficients ( $r 0 \cdot 2$ and $0 \cdot 8)$, and then by comparing the results with the imputed correlation coefficient chosen for the meta-analysis ( $r$ 0.5). Subgroup analysis of interventions with sesame consumption for $\geq 8$ weeks was compared with those with intervention duration of $<8$ weeks. Sources of sesame (whole or ground $v$. oil) were chosen for another subgroup analysis. The influence of the intervention design was assessed by comparing the difference in the meta-analysis results of the parallel against cross-over design trials. Finally, the influence of body weight on meta-analysis results was assessed by comparing the subgroup of studies with participants with mean baseline BMI of $\geq 30 \mathrm{~kg} / \mathrm{m}^{2}$ against those with BMI $<30 \mathrm{~kg} / \mathrm{m}^{2}$.

\section{Results}

Overview of the studies and their quality

A total of ten trials (908 participants) that examined the effect of sesame consumption on blood lipid profiles were included 
in the systematic review and meta-analysis. Of these, three studies $^{(10,24-30)}$ had the lowest Rosendal score of $50 \%$ (online Supplemental Table S1). The highest Rosendal score of $93 \%$ was calculated for the studies conducted by Wu et al. ${ }^{(31)}$ and Helli et $a l .{ }^{(32)}$. Four of the studies had a cross-over $\operatorname{design}^{(10,31-33)}$, and the rest of the studies used a parallel design. Three studies reported using a double-blind design ${ }^{(31,32-34)}$, and one study reported using a single-blind design ${ }^{(35)}$. The remaining studies did not mention blinding of the participants or the investigators.

\section{Characteristics of participants and studies}

Table 1 presents the characteristics of the included trials. Changes in total cholesterol, TAG, LDL-cholesterol and HDLcholesterol were reported in all studies. The ten trials included different types of participants: two included hypertensives ${ }^{(10,30)}$; one diabetics ${ }^{(34)}$; one hypertensives and diabetics ${ }^{(10)}$; one hyperlipidaemia patients ${ }^{(36)}$; one haemodialysis participants ${ }^{(37)}$; one rheumatoid arthritis patients ${ }^{(32)}$; and one overweight and obese individuals $^{(31)}$. Among all included trials, three studies included only female participants ${ }^{(32,33,35)}$. Five studies used sesame oil for the intervention ${ }^{(10,24,30,35,37)}$, and the remaining trials used the seed or ground powdered sesame or its extracts $^{(31-34,36)}$. Three studies reported a significant reduction in body weight after consuming sesame ${ }^{(10,24-32)}$, and one study reported a significant increase in body weight in the intervention group ${ }^{(33)}$. The remainder of the studies did not report significant changes in body weight in any of the groups.

The majority of trials did not report measuring dietary intake of the participants, with only four studies ${ }^{(31,32-35-38)}$ using a 3-d food record method to measure dietary intake before and after intervention in order to determine any potential dietary changes. No significant differences were reported between control and intervention groups at baseline in any of these studies. Lemcke-Norojärvi et $a l .{ }^{(35)}$ reported a significantly lower intake of PUFA as the difference between the oil consumed between control and intervention groups. Mirmiran et al. ${ }^{(34)}$ also reported that the sesame group had a higher intake of total fat as a result of intervention. Three studies reported that participants received advice to maintain their usual diet ${ }^{(32,33-35)}$ or to avoid adding foods to their diet that contain sesame during the intervention $^{(34)}$.

\section{Information on supplement protocol}

Three of the trials reported using capsules as the vehicle for sesame supplementation ${ }^{(32,33-37)}$. One used breakfast bars ${ }^{(31)}$ and the remaining studies used sesame oil replacement of all oils consumed or a mixture of ground sesame in a variety of foods. A wide variation in daily dose of sesame consumption was observed between the studies. Daily sesame oil consumption varied from using capsules of $3.5 \mathrm{~g} \mathrm{oil}^{(37)}$ to $35 \mathrm{~g}$ of sesame oil replacing the common oil used by participants daily ${ }^{(10,24-30)}$. Overall sesame (ground, powdered or whole seed) consumption varied from $25^{(31)}$ to $50 \mathrm{~g} / \mathrm{d}^{(33)}$. Study duration varied from $4^{(35)}$ to 10 weeks $^{(33)}$. None of the studies reported any significant side-effects.

\section{Meta-analysis results}

The forest plots of the meta-analysis effect of sesame consumption on blood lipid profile are presented in Figs. 2-5. Consumption of sesame did not significantly reduce total blood cholesterol levels $(-0.32 \mathrm{mmol} / 1 ; 95 \% \mathrm{CI}-0.75,0 \cdot 11 ; P=0 \cdot 14$, $I^{2}=96 \%$ ) (Fig. 2). However, a significant meta-analysis effect of sesame consumption was observed for the mean difference in TAG levels $(-0.24 \mathrm{mmol} / 1 ; 95 \%$ CI $-0.32,-0 \cdot 15 ; \quad P<0.001$, $I^{2}=84 \%$ ) (Fig. 3). The meta-analysis for the effect of sesame consumption on the mean difference of LDL-cholesterol was not significant $(-0.15 \mathrm{mmol} / 1 ; 95 \%$ CI $-0.50,0.19 ; P=0.39$, $I^{2}=96 \%$ ) (Fig. 4). No significant change in the mean difference of HDL-cholesterol after consumption of sesame was observed (0.01 mmol $/ 1 ; 95 \% \mathrm{CI}-0 \cdot 00,0 \cdot 02 ; P=0 \cdot 16, I^{2}=0 \%$ ) (Fig. 5).

\section{Sensitivity and subgroup analysis}

The one-by-one sensitivity analysis did not show a significant effect of individual studies on the overall meta-analysis of the effect of sesame consumption on lipid profiles. Sensitivity analysis of alternative correlation coefficients ( $r \quad 0.2$ and 0.8 ) showed agreement between the direction of the effect with the chosen correlation coefficient. These results showed the robustness of the meta-analysis results using the chosen correlation coefficient of $0 \cdot 5$.

Subgroup analyses of the effect of sesame consumption on total cholesterol did not identify any study characteristics that could have moderated the results of the meta-analyses (Table 2). The duration of intervention, source of sesame (seed or oil) or baseline BMI of participants had no significant influence on the subgroup analysis results. Subgroup analysis of the design of the studies (parallel or cross-over) also did not significantly affect the mean difference of total cholesterol. Further, the test of the difference between subgroups did not reveal any significant results (Table 2).

A number of study characteristics seem to influence the effect of sesame consumption on blood TAG levels. Subgroup analysis by duration of intervention showed significant reduction in TAG levels in both durations $\geq 8$ and $<8$ weeks. The reduction observed in the subgroup of interventions with duration of $<8$ weeks $(n=4)$ was slightly more pronounced compared with duration of $\geq 8$ weeks $(n=4)(-0.26 v .-0.16 \mathrm{mmol} / \mathrm{l})$. Nevertheless, the test for subgroup differences was not significant $\left(I^{2}=7 \%, P=0 \cdot 30\right.$ ) (Table 2). Subgroup analysis of the effect of the source of sesame showed a significant reduction in TAG levels when sesame was consumed as oil $(n=5)(-0.27 \mathrm{mmol} / \mathrm{l}$; $95 \%$ CI $-0 \cdot 36,-0 \cdot 17 ; P<0 \cdot 001)$. No meaningful effect of sesame consumption on TAG levels was observed in the subgroup of sesame as whole or ground seed $(n=5)$. Although the test for subgroup differences of source of sesame did not reach statistical significance, a trend was observed $\left(I^{2}=71 \%, P=0.06\right)$ (Table 2). The baseline BMI of participants had an influence on TAG level changes following sesame consumption. The subgroup of baseline BMI $<30 \mathrm{~kg} / \mathrm{m}^{2}(n=7)$ had a significant reduction in TAG levels $(-0.25 \mathrm{mmol} / 1 ; 95 \% \mathrm{CI}-0 \cdot 35,-0 \cdot 15$; $P<0.001)$. However, no significant effect was observed in the subgroup of studies with BMI $\geq 30 \mathrm{~kg} / \mathrm{m}^{2}(n=7)$. The test for 
Table 1. Characteristics of studies evaluating the effect of sesame on blood lipid profile

(Mean values and standard deviations; mean of changes and standard deviations of change)

\begin{tabular}{|c|c|c|c|c|c|c|c|c|c|c|c|c|c|c|c|c|c|c|}
\hline \multirow[b]{2}{*}{ Study (year) } & \multirow[b]{2}{*}{ Design; location } & \multirow[b]{2}{*}{ Intervention/control } & \multirow[b]{2}{*}{$\begin{array}{l}\text { Duration } \\
\text { (weeks) }\end{array}$} & \multirow[b]{2}{*}{ Source } & \multirow[b]{2}{*}{$\begin{array}{l}\text { Dose } \\
\text { (per d) }\end{array}$} & \multirow[b]{2}{*}{ Participants } & \multicolumn{2}{|c|}{ Age (years) } & \multicolumn{2}{|c|}{ Participants } & \multicolumn{2}{|c|}{ Intervention Baseline } & \multicolumn{2}{|c|}{$\begin{array}{c}\text { Changes } \\
\text { from } \\
\text { baseline }\end{array}$} & \multicolumn{2}{|c|}{$\begin{array}{l}\text { Control baseline } \\
(\mathrm{mmol} / \mathrm{l})\end{array}$} & \multicolumn{2}{|c|}{$\begin{array}{c}\text { Changes } \\
\text { from } \\
\text { baseline }\end{array}$} \\
\hline & & & & & & & Mean & SD & $\begin{array}{l}\text { Intervention; } \\
\text { control } n\end{array}$ & $\mathrm{M} / \mathrm{F}$ & Mean & SD & Mean & SD & Mean & SD & Mean & SD \\
\hline Alipoor (2012) & R, C; Iran & $\begin{array}{l}\text { Sesame seed/control } \\
\text { placebo }\end{array}$ & 8 & Seeds & $40 \mathrm{~g}$ & Hyper lipid & \multicolumn{2}{|c|}{$50-70$} & $19 ; 19$ & $30 / 8$ & $\begin{array}{l}\text { TC: } 6 \cdot 23 \\
\text { TAG: } 1 \cdot 9 \\
\text { LDL:4:13 } \\
\text { HDL: } 1 \cdot 2\end{array}$ & $\begin{array}{l}1.06 \\
0.83 \\
0.97 \\
0.21\end{array}$ & $\begin{array}{l}-0.51 \\
-0.14 \\
-0.41 \\
-0.01\end{array}$ & $\begin{array}{l}1.11 \\
0.81 \\
1.05 \\
0.2\end{array}$ & $\begin{array}{l}\text { TC: } 5.92 \\
\text { TAG: } 1.99 \\
\text { LDL: } 3.74 \\
\text { HDL: } 1.27\end{array}$ & $\begin{array}{l}0.81 \\
0.97 \\
0.92 \\
0.25\end{array}$ & $\begin{array}{r}0.06 \\
0.21 \\
-0.04 \\
-0.03\end{array}$ & $\begin{array}{l}0.79 \\
1.04 \\
0.88 \\
0.24\end{array}$ \\
\hline Khajehdehi (2000) & R, PC; Iran & Sesame oil/maize oil & 8 & Capsule & $4.5 \mathrm{~g}$ & Haemodialysis & $32 \cdot 3$ & 6.8 & $15 ; 15$ & $16 / 14$ & $\begin{array}{l}\text { TC: } 4.45 \\
\text { TAG: } 5.03 \\
\text { LDL:2.53 } \\
\text { HDL: } 1.02\end{array}$ & $\begin{array}{l}0.42 \\
0.05 \\
0.29 \\
0.56\end{array}$ & $\begin{array}{r}-0.23 \\
-0.34 \\
0.03 \\
0.26\end{array}$ & $\begin{array}{l}2.8 \\
0.04 \\
2.01 \\
0.52\end{array}$ & $\begin{array}{c}\text { TC: } 4.93 \\
\text { TAG: } 4.46 \\
\text { LDL: } 3.19 \\
\text { HDL: } 0.88\end{array}$ & $\begin{array}{l}1.39 \\
0.01 \\
1.24 \\
0.19\end{array}$ & $\begin{array}{r}-0.09 \\
-0.18 \\
-0.61 \\
0.54\end{array}$ & $\begin{array}{l}1.25 \\
0.01 \\
1.11 \\
0.28\end{array}$ \\
\hline Helli (2015) & $\begin{array}{l}\mathrm{R}, \mathrm{PC}, \mathrm{CO}, \mathrm{DB} ; \\
\text { Iran }\end{array}$ & Sesamin/starch & 6 & Capsule & $200 \mathrm{mg}$ & RA female & 55.5 & 6.0 & 22 & $0 / 22$ & $\begin{array}{l}\text { TC: } 5.33 \\
\text { TAG: } 1.92 \\
\text { HDL: } 1.53 \\
\text { LDL: } 2.71\end{array}$ & $\begin{array}{l}0.85 \\
0.66 \\
0.27 \\
0.69\end{array}$ & $\begin{array}{r}-0.36 \\
-0.11 \\
0.02 \\
-0.29\end{array}$ & $\begin{array}{l}0.76 \\
0.84 \\
0.24 \\
0.62\end{array}$ & $\begin{array}{l}\text { TC: } 5 \cdot 13 \\
\text { TAG: } 2 \cdot 00 \\
\text { HDL: } 1.47 \\
\text { LDL: } 2.62\end{array}$ & $\begin{array}{l}1.22 \\
0.81 \\
0.27 \\
0.79\end{array}$ & $\begin{array}{l}-0.06 \\
-0.09 \\
-0.10 \\
-0.27\end{array}$ & $\begin{array}{l}1.12 \\
1.12 \\
0.19 \\
0.83\end{array}$ \\
\hline $\begin{array}{l}\text { Lemcke-Norojärvi } \\
\text { (2001) }\end{array}$ & $\begin{array}{l}\text { R, PC, P, SB; } \\
\text { Sweden }\end{array}$ & Sesame/maize oil & 4 & Buns & 22.5 & $\begin{array}{l}\text { Healthy } \\
\text { female }\end{array}$ & 27.6 & 6.5 & $10 ; 13$ & $0 / 23$ & $\begin{array}{c}\text { TC: } 4 \cdot 2 \\
\text { TAG: } 0.80 \\
\text { LDLL: } 2 \cdot 49 \\
\text { HDL: } 1 \cdot 40\end{array}$ & $\begin{array}{l}0.80 \\
0.36 \\
0.60 \\
0.23\end{array}$ & $\begin{array}{l}-0.15 \\
-0.08 \\
-0.01 \\
-0.02\end{array}$ & $\begin{array}{l}0.74 \\
0.33 \\
0.59 \\
0.24\end{array}$ & $\begin{array}{c}\text { TC: } 4.52 \\
\text { TAG: } 0.87 \\
\text { LDLL:288 } \\
\text { HDL: } 1.33\end{array}$ & $\begin{array}{l}0.72 \\
0.34 \\
0.58 \\
0.29\end{array}$ & $\begin{array}{r}-0.02 \\
0.06 \\
-0.06 \\
0.02\end{array}$ & $\begin{array}{l}0.68 \\
0.31 \\
0.56 \\
0.27\end{array}$ \\
\hline Mirmiran (2013) & R, C, P, DB; Iran & Sesame/control & 6 & $\begin{array}{l}\text { Ground } \\
\text { seeds }\end{array}$ & $28 \mathrm{~g}$ & DM & $18-6$ & & $20 ; 16$ & $8 / 28$ & $\begin{array}{l}\text { TC: } 5 \cdot 17 \\
\text { TAG: } 1.85 \\
\text { LDL:3.12 } \\
\text { HDL: } 1.30\end{array}$ & $\begin{array}{l}0.48 \\
1.0 \\
1.3 \\
0.42\end{array}$ & $\begin{array}{r}-0.29 \\
-0.23 \\
-0.31 \\
0.02\end{array}$ & $\begin{array}{l}1.51 \\
0.99 \\
1.28 \\
0.41\end{array}$ & $\begin{array}{c}\text { TC: } 4.62 \\
\text { TAG: } 1 \cdot 7 \\
\text { LDL: } 2.58 \\
\text { HDL: } 1 \cdot 24\end{array}$ & $\begin{array}{l}0.53 \\
0.6 \\
1.06 \\
0.25\end{array}$ & $\begin{array}{c}0.24 \\
0.27 \\
0.1 \\
-0.03\end{array}$ & $\begin{array}{l}1.98 \\
0.58 \\
1.04 \\
0.24\end{array}$ \\
\hline Sankar (2005) & C; India & $\begin{array}{l}\text { Sesame oil/sunflower } \\
\text { oil }\end{array}$ & 8 & Oil in food & $35 \mathrm{~g}$ & HTN & $\begin{array}{r}\text { Midd } \\
\text { age }\end{array}$ & & $356 ; 87^{*}$ & & $\begin{array}{c}\text { TC: } 5 \cdot 34 \\
\text { TAG: } 2 \cdot 07 \\
\text { LDL:3:25 } \\
\text { HDL: } 1 \cdot 14\end{array}$ & $\begin{array}{l}0.47 \\
0.1 \\
0.33 \\
0.09\end{array}$ & $\begin{array}{c}-0.85 \\
-0.39 \\
-0.78 \\
0.1\end{array}$ & $\begin{array}{l}0.42 \\
0.14 \\
0.31 \\
0.08\end{array}$ & $\begin{array}{c}\text { TC: } 5 \cdot 34 \\
\text { TAG: } 2 \cdot 07 \\
\text { LDL: } 3 \cdot 25 \\
\text { HDL: } 1 \cdot 14\end{array}$ & $\begin{array}{l}0.47 \\
0.1 \\
0.33 \\
0.09\end{array}$ & $\begin{array}{r}-0.77 \\
-0.22 \\
-0.77 \\
0.09\end{array}$ & $\begin{array}{l}0.47 \\
0.14 \\
0.29 \\
0.08\end{array}$ \\
\hline Sankar (2006a) & CO; India & Sesame/regular oil & 6 & Oil in food & $35 \mathrm{~g}$ & $\mathrm{HTN}+\mathrm{DM}$ & $45-6$ & & 40 & $22 / 18$ & $\begin{array}{l}\text { TC: } 6 \cdot 48 \\
\text { TAG: } 2 \cdot 66 \\
\text { LDL:4.11 } \\
\text { HDL: } 1 \cdot 23\end{array}$ & $\begin{array}{l}0.19 \\
0.1 \\
0.22 \\
0.02\end{array}$ & $\begin{array}{r}-1.16 \\
-0.62 \\
-0.98 \\
0.01\end{array}$ & $\begin{array}{l}0.34 \\
0.13 \\
0.29 \\
0.02\end{array}$ & $\begin{array}{l}\text { TC: } 6 \cdot 48 \\
\text { TAG: } 2 \cdot 66 \\
\text { LDL:4:11 } \\
\text { HDL: } 1 \cdot 23\end{array}$ & $\begin{array}{l}0.19 \\
0.1 \\
0.22 \\
0.02\end{array}$ & $\begin{array}{r}0.03 \\
-0.33 \\
0.02 \\
0.02\end{array}$ & $\begin{array}{l}0.16 \\
0.1 \\
0.19 \\
0.02\end{array}$ \\
\hline Sankar (2006b) & R, CO; India & Sesame/regular oil & 6 & Oil in food & $35 \mathrm{~g}$ & HTN & $35-6$ & & $50 ; 50$ & $32 / 18$ & $\begin{array}{l}\text { TC: } 5 \cdot 68 \\
\text { TAG: } 5 \cdot 03 \\
\text { LDL:3.51 } \\
\text { HDL: } 1 \cdot 18\end{array}$ & $\begin{array}{l}0.4 \\
0.21 \\
0.18 \\
0.06\end{array}$ & $\begin{array}{r}-0.07 \\
-0.92 \\
0.05 \\
0.03\end{array}$ & $\begin{array}{l}0.43 \\
0.22 \\
0.24 \\
0.05\end{array}$ & $\begin{array}{l}\text { TC: } 5.68 \\
\text { TAG: } 5 \cdot 03 \\
\text { LDL:3.51 } \\
\text { HDL: } 1 \cdot 18\end{array}$ & $\begin{array}{l}0.4 \\
0.21 \\
0.18 \\
0.06\end{array}$ & $\begin{array}{r}0.08 \\
-0.38 \\
0.08 \\
0.02\end{array}$ & $\begin{array}{l}0.46 \\
0.25 \\
0.36 \\
0.06\end{array}$ \\
\hline Wu (2006) & $\begin{array}{l}\text { R, PC, CO; } \\
\text { Taiwan }\end{array}$ & Sesame/rice powder & 10 & Capsule & $50 \mathrm{~g}$ & PM female & 59 & 7 & 24 & $0 / 24$ & $\begin{array}{l}\text { TC: } 5 \cdot 37 \\
\text { TAG: } 1 \cdot 07 \\
\text { LDL:3.03 } \\
\text { HDL: } 1.33\end{array}$ & $\begin{array}{l}0.93 \\
0.30 \\
0.97 \\
0.33\end{array}$ & $\begin{array}{r}-0.32 \\
0.04 \\
-0.31 \\
-0.02\end{array}$ & $\begin{array}{l}0.89 \\
0.40 \\
0.90 \\
0.33\end{array}$ & $\begin{array}{l}\text { TC: } 5 \cdot 41 \\
\text { TAG: } 1.03 \\
\text { LDL:3.19 } \\
\text { HDL: } 1.35\end{array}$ & $\begin{array}{l}0.91 \\
0.34 \\
0.70 \\
0.29\end{array}$ & $\begin{array}{r}-0.06 \\
0.14 \\
-0.05 \\
-0.02\end{array}$ & $\begin{array}{l}0.87 \\
0.39 \\
0.28 \\
0.30\end{array}$ \\
\hline Wu (2009) & $\begin{array}{l}\text { R, PC, CO, DB; } \\
\text { Australia }\end{array}$ & $\begin{array}{l}\text { Sesame seed bars/ } \\
\text { plain bars }\end{array}$ & 5 & $\begin{array}{c}\text { Breakfast } \\
\text { bars }\end{array}$ & $25 \mathrm{~g}$ & OW, OB & 54.7 & 8.6 & 33 & $17 / 16$ & $\begin{array}{c}\text { TC: } 5.84 \\
\text { TAG: } 1.47 \\
\text { LDL:3.75 } \\
\text { HDL: } 1.37\end{array}$ & $\begin{array}{l}0.84 \\
0.47 \\
0.76 \\
0.38\end{array}$ & $\begin{array}{c}0 \\
-0.12 \\
0.07 \\
0\end{array}$ & $\begin{array}{l}0.84 \\
0.45 \\
0.80 \\
0.38\end{array}$ & $\begin{array}{c}\text { TC: } 5.94 \\
\text { TAG: } 1.51 \\
\text { LDL: } 3.84 \\
\text { HDL: } 1.36\end{array}$ & $\begin{array}{l}0.82 \\
0.38 \\
0.75 \\
0.38\end{array}$ & $\begin{array}{l}-0.11 \\
-0.16 \\
-0.03 \\
-0.01\end{array}$ & $\begin{array}{l}0.81 \\
0.41 \\
0.73 \\
0.37\end{array}$ \\
\hline
\end{tabular}

M, male; F, female; R, randomised; C, controlled; TC, total cholesterol; PC, placebo control; CO, cross-over; DB, double-blind; RA, rheumatoid arthritis; P, parallel; SB, single blind; DM, diabetes mellitus; HTN, hypertension; PM, post-

menopausal; OW, overweight; OB, obesity.
* No information on sex distribution was provided in the trial. 


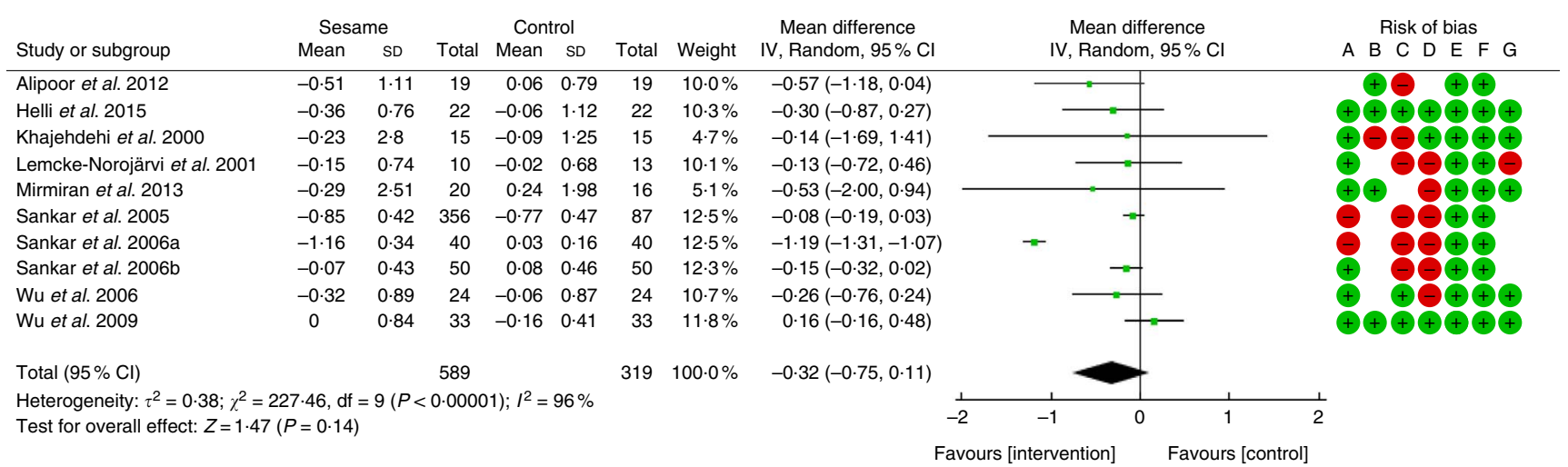

Fig. 2. Forest plot and risk of bias of the effect of sesame consumption on blood total cholesterol levels. A random effect model was used to analyse the effectiveness of intervention. Effect of each trial was presented as weight (\%) as well as mean difference and $95 \% \mathrm{Cl}$. Risk of bias legend: (A) random sequence generation (selection bias); (B) allocation concealment (selection bias); (C) blinding of participants and personnel (performance bias); (D) blinding of outcome assessment (detection bias); (E) incomplete outcome data (attrition bias); (F) selective reporting (reporting bias); (G) other bias.

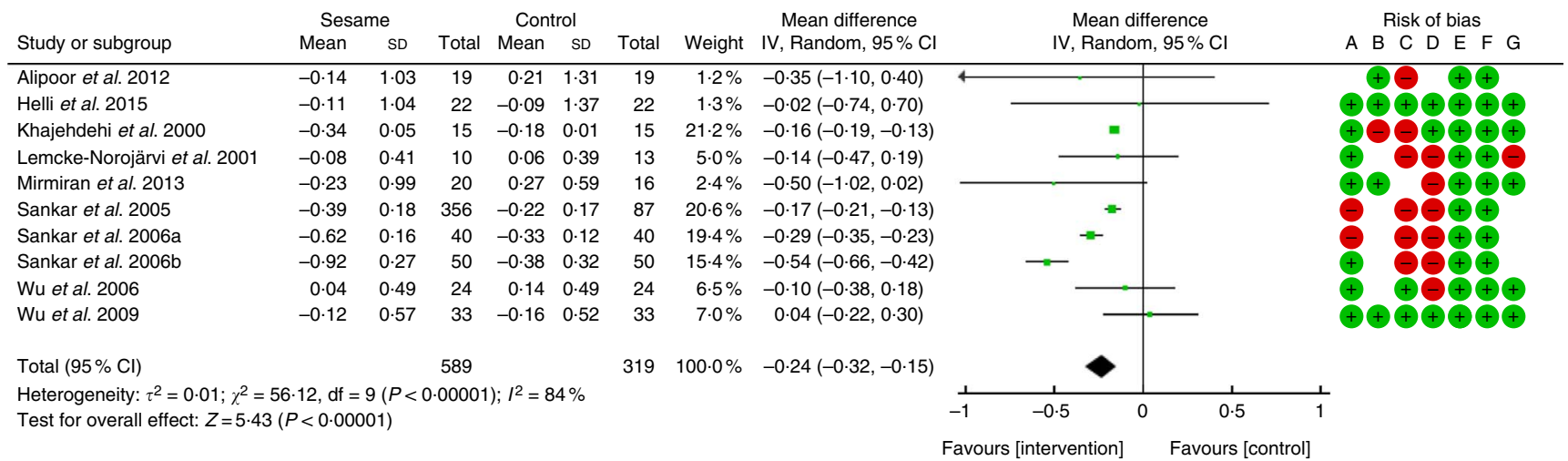

Fig. 3. Forest plot and risk of bias of the effect of sesame consumption on blood TAG levels. A random effect model was used to analyse the effectiveness of intervention. Effect of each trial was presented as weight (\%) as well as mean difference and $95 \% \mathrm{Cl}$. Risk of bias legend: (A) random sequence generation (selection bias); (B) allocation concealment (selection bias); (C) blinding of participants and personnel (performance bias); (D) blinding of outcome assessment (detection bias); (E) incomplete outcome data (attrition bias); (F) selective reporting (reporting bias); (G) other bias.

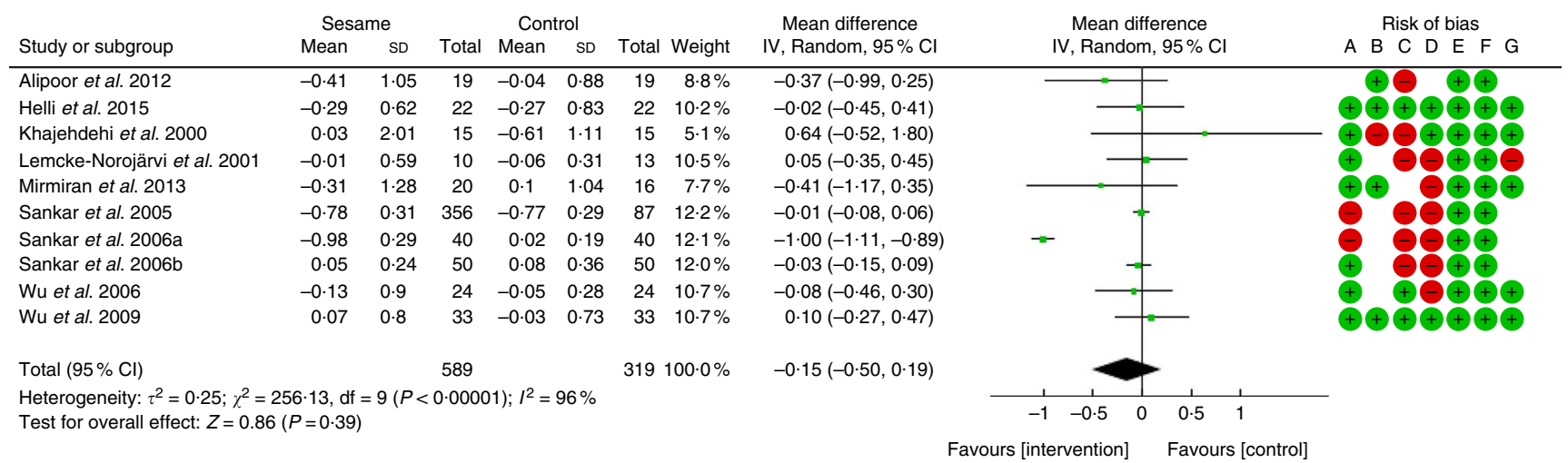

Fig. 4. Forest plot and risk of bias of the effect of sesame consumption on blood LDL-cholesterol levels. A random effect model was used to analyse the effectiveness of intervention. Effect of each trial was presented as weight (\%) as well as mean difference and $95 \% \mathrm{Cl}$. Risk of bias legend: (A) random sequence generation (selection bias); (B) allocation concealment (selection bias); (C) blinding of participants and personnel (performance bias); (D) blinding of outcome assessment (detection bias); (E) incomplete outcome data (attrition bias); (F) selective reporting (reporting bias); (G) other bias.

subgroup analysis showed no significant difference between baseline BMI subgroups $\left(I^{2}=0 \%, P=0 \cdot 40\right)$. Both parallel and cross-over design subgroups showed significant reduction in TAG levels. The reduction was more pronounced in the subgroup of cross-over design compared with parallel design studies $(-0.23 v .-0 \cdot 16 \mathrm{mmol} / \mathrm{l})$. No significant difference was observed between the study design subgroups (Table 2).

The subgroup analyses of the effect of duration of intervention on LDL-cholesterol did not result in significant differences (Table 2). The source of sesame consumption (oil or seed) also 
Sesame and lipid profiles

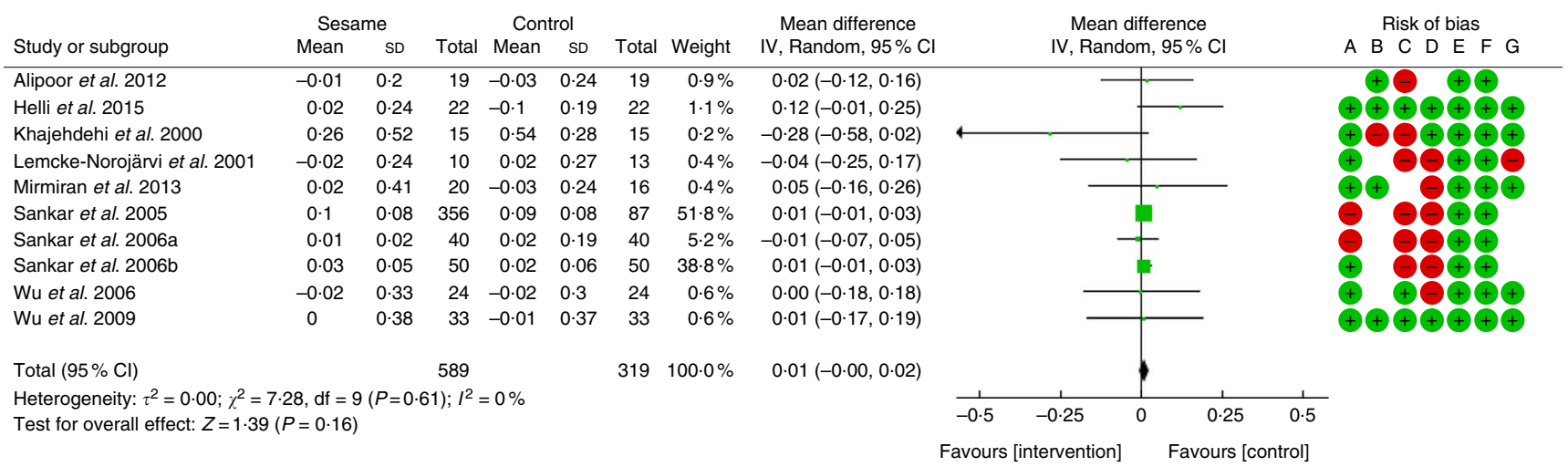

Fig. 5. Forest plot and risk of bias of the effect of sesame consumption on blood HDL-cholesterol levels. A random effect model was used to analyse the effectiveness of intervention. Effect of each trial was presented as weight (\%) as well as mean difference and $95 \% \mathrm{Cl}$. Risk of bias legend: (A) random sequence generation (selection bias); (B) allocation concealment (selection bias); (C) blinding of participants and personnel (performance bias); (D) blinding of outcome assessment (detection bias); (E) incomplete outcome data (attrition bias); (F) selective reporting (reporting bias); (G) other bias.

did not have any significant influence on LDL-cholesterol changes. Similar results were observed for the effect of the design of the studies. However, baseline BMI of participants had a more pronounced effect on the subgroup meta-analysis of the effect of sesame consumption on LDL-cholesterol. A 0.32 reduction in LDL-cholesterol was observed in the subgroup of studies with baseline BMI $\geq 30 \mathrm{~kg} / \mathrm{m}^{2}$, but the reduction did not reach statistical significance (Table 2 ).

None of the characteristics of the studies was found to have a significant influence on the subgroup analysis of the effect of sesame consumption on blood HDL-cholesterol (Table 2). It appears that the different duration of sesame consumption, the source of sesame or the design of studies do not have any moderating influence on the meta-analysis of the effect of sesame on HDL-cholesterol. Similar results were observed with regard to the different baseline BMI of participants (Table 2).

\section{Discussion}

To our knowledge, the present meta-analysis is the first quantitative review of controlled trials on the effect of sesame consumption on serum lipid profiles. The present meta-analysis showed that sesame consumption significantly reduced TAG concentrations but not total cholesterol, HDL-cholesterol or LDL-cholesterol concentrations. Although a neutral effect of sesame consumption on total cholesterol, HDL-cholesterol and LDL-cholesterol was observed, the significant TAG reduction reported by the meta-analysis of this study may have pivotal clinical and public health implications.

Although the association between increased total cholesterol and LDL-cholesterol and reduced HDL-cholesterol and the risk of CVD is well studied, elevated TAG levels have been recently considered as a single important risk factor of $\mathrm{CVD}^{(39)}$. The management of dyslipidaemia (characterised by elevated levels of total cholesterol, LDL-cholesterol and TAG and reduced levels of HDL-cholesterol) involves a variety of approaches such as pharmacotherapy and lifestyle modification that can be adapted to control the lipid levels. However, many patients treated with anti-dyslipidaemic drugs do not achieve satisfactory results and still remain at high risk for CVD ${ }^{(40)}$. For instance, statins, which are the most commonly used lipidlowering drugs, at maximum dosage can reduce LDLcholesterol only by $50-55 \%{ }^{(41)}$. However, such dosages are often not well tolerated, and $10-15 \%$ of patients report statin intolerance $^{(42)}$. Considering the limitation of the antidyslipidaemic drugs, there is a great deal of interest in nutraceuticals that may possibly complement the pharmaceutical treatments. Food and dietary supplementation and nutraceuticals may affect lipids through complicated mechanisms that affect the absorption and metabolism of lipids ${ }^{(41)}$.

Sesame, as one of these potential dietary factors, contains several lignans such as sesamolin, sesaminol and sesamin, which can be absorbed by the intestines, and through the portal vein they reach the liver where they metabolise into catechol derivatives ${ }^{(43)}$. The catechol metabolites from sesamin have a strong antioxidative activity on the liver ${ }^{(44)}$, and they can affect the metabolism and production of lipids ${ }^{(17-19)}$. Its potential cholesterol-lowering effects may be due to the inhibition of the 3-hydroxy-3-methylglutaryl-coenzyme A reductase activity, which is the enzyme involved in the synthesis of cholesterol ${ }^{(17)}$. In addition, TAG-lowering properties of sesame can be partially explained by its high MUFA contents ( $40 \%$ in sesame oil) ${ }^{(10)}$. The American Heart Association has reported that high dietary MUFA intake is likely to decrease blood TAG concentrations ${ }^{(8)}$. Evidence from the meta-analysis shows that a short-term intervention with a MUFA-rich diet can reduce the serum levels of TAG and HDLcholesterol $^{(45)}$. In addition, the high content of fibre, vitamin $\mathrm{E}$ and PUFA in sesame seeds, as well as the antioxidant activity of its lignans, can affect TAG generation and metabolism ${ }^{(10)}$. It has been described that PUFA consumption reduces the risk of CVD by decreasing serum TAG levels and by modestly increasing serum HDL-cholesterol concentrations ${ }^{(46)}$. Furthermore, the biological effectiveness of nutrients, such as antioxidant activity, can be enhanced by their interaction with other components in the $\operatorname{diet}^{(47)}$. Sesame lignans in combination with $\alpha$-tocopherol (precursor of vitamin E) were more effective on lipid peroxidation than as a single compound ${ }^{(48)}$. The literature also reports that certain lignans in sesame seeds and oil can elevate plasma and tissue levels of vitamin E precursors ( $\alpha$ - and $\gamma$-tocopherol) ${ }^{(49,50)}$. 
Table 2. Results of subgroup analyses of included randomised-controlled trials in the meta-analysis of sesame consumption and blood lipid profile* (Mean differences and $95 \% \mathrm{Cl}$; heterogeneity $\left(I^{2}\right)$ )

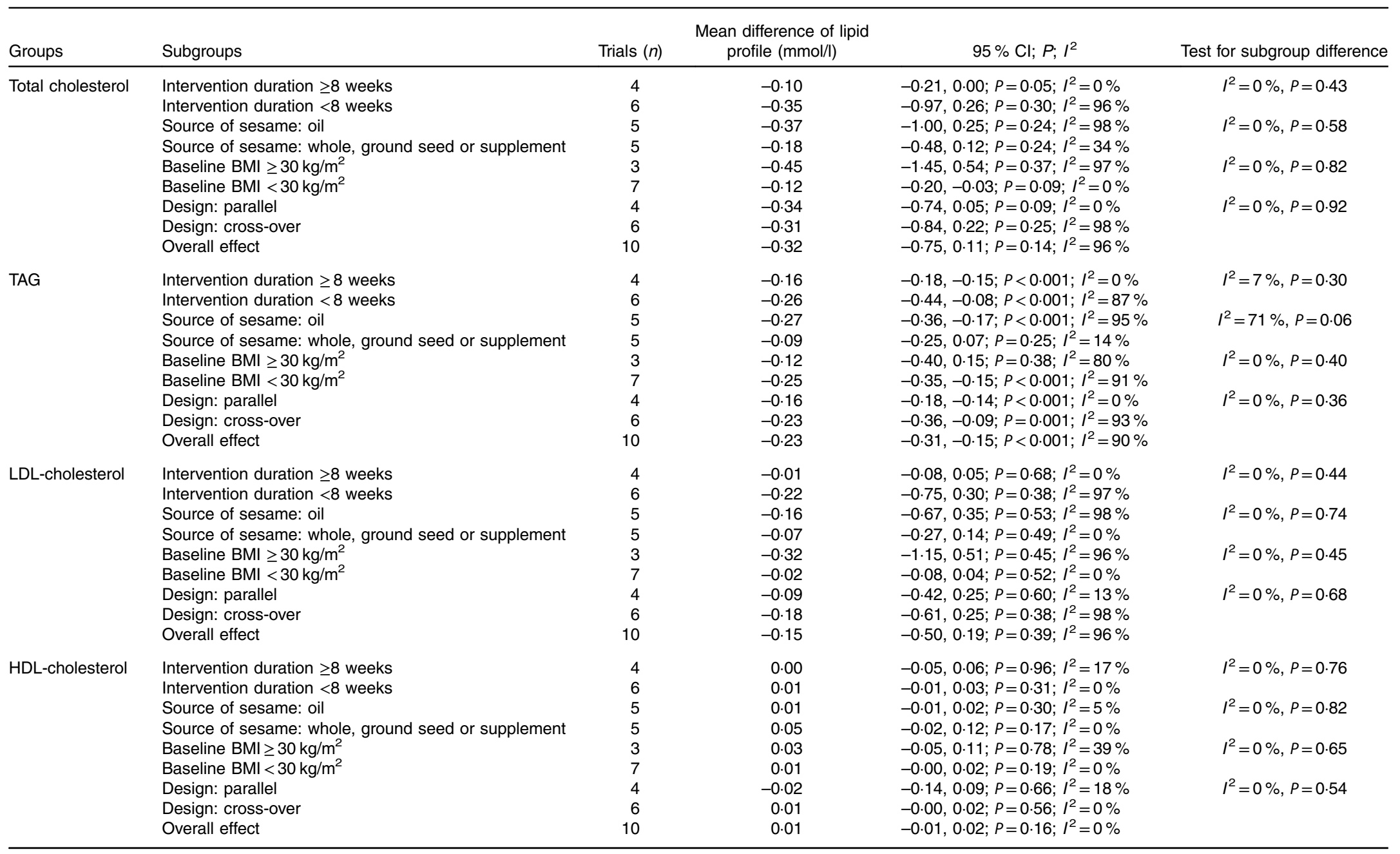

* Removing two studies by Sankar et al. ${ }^{(10,24)}$ without the complete cross-over design changed the subgroup analysis to non-significant effect. A $P$ value $<0.05$ is considered significant. 
Dietary sesame lignans may also influence the gene expressions of various lipid metabolism enzymes involved in lipogenesis and $\beta$-oxidation and also influence the expressions of proteins involved in transportation of fatty acids ${ }^{(43)}$.

This meta-analysis found that sesame consumption significantly decreased TAG levels. The results of subgroup analyses showed that the source of sesame intake moderates the effects of sesame intake on TAG levels. Consuming sesame as oil (but not as whole or ground seeds) has significant reducing effects on TAG levels. A more pronounced effect of sesame on TAG levels was also observed in the subgroup with BMI $<30 \mathrm{~kg} / \mathrm{m}^{2}$. There is no logical explanation for the observed findings. However, the difference observed in the subgroup of BMI can be due to the lower number of trials included in the subgroup of BMI $\geq 30 \mathrm{~kg} / \mathrm{m}^{2}$. Further interventions with a focus on higher BMI need to confirm the effect of sesame observed in this study. Subgroup analyses for duration and design of intervention did not affect the results. A neutral effect of sesame consumption on total cholesterol, LDL-cholesterol and HDL-cholesterol was observed in the present meta-analysis. Subgroup analysis of the effect of sesame intake on cholesterol or lipoprotein levels did not moderate the outcome. These findings are generally in line with the majority of individual studies selected for this review. Only one study showed a significant change in cholesterol levels ${ }^{(10)}$ and others failed to find such a relationship.

In vitro studies showed that sesaminol inhibits peroxidation of LDL-cholesterol ${ }^{(51,52)}$, and therefore sesame consumption may have a protective role in atherogenesis ${ }^{(53)}$. Animal studies have also reported that sesamin decreases the synthesis of fatty acids in the liver, down-regulates transcriptional factors ${ }^{(54)}$, increases the activity of $\beta$-oxidation-associated enzymes and decreases hepatic arachidonic acid and EPA concentrations ${ }^{(55)}$. The suggested mechanisms for the effect of sesame on human lipid profiles are not entirely similar to those of animal studies. For instance, peroxisome proliferation that corresponds to increased peroxisomal fatty acid $\beta$-oxidation activity can be activated in rodents but not in humans ${ }^{(56)}$. In addition, the dose of sesame consumption can have an influence on the effect of sesame on lipid profiles. There is a dose-dependent association between gene expression of hepatic beta-oxidation enzymes and sesamin intake ${ }^{(19)}$. Therefore, higher amounts of sesame intake may have different results on cholesterol levels in humans. However, the dose-dependency effect analysis was not applicable in this meta-analysis because of the differences between the sesame sources (oil, lignans) and difficulties in accurate dose conversions.

The present meta-analysis has a number of limitations that need to be considered. First, a small number of controlled trials was included in this review. The characteristics of included studies varied widely in terms of health status, sex and age of participants, study duration and sources and the dosage of sesame. In addition, a significant heterogeneity was detected between the studies in the meta-analysis. Sensitivity analyses attempted to highlight the influence of study characteristics on the heterogeneity and overall meta-analysis results. However, the wide variation in the characteristics of included studies limited the subgroup analysis. The limited number of studies also raised the heterogeneity of analyses. Furthermore, the majority of trials did not control for dietary changes of participants during the intervention, which may have influenced the accuracy of the results. Moreover, one study with low quality assessment scores was excluded from the quantitative synthesis, which could have skewed the meta-analysis results ${ }^{(57)}$. Finally, only studies published in English language were included in this study. This may have resulted in the exclusion of quality studies that were published in other languages. Nevertheless, this study systematically reviewed the effects of sesame on lipid profiles and increased the power of conclusion by using meta-analysis of controlled trials.

\section{Conclusion}

Consumption of sesame can significantly reduce blood TAG levels. Despite not having adequate evidence to support the hypocholesterolaemic effects of sesame, the question of whether a higher dosage or longer duration of sesame consumption would have such effects remains unanswered. Therefore, there is a need for further investigation of sesame consumption as a complementary dietary constituent to determine its potential effects on improving lipid profiles and, in turn, reducing the risk of CVD.

\section{Acknowledgements}

This research received no specific grant from any funding agency, commercial or not-for-profit sectors.

S. K. and H. K.-B. designed the study; S. K., H. K.-B., E. P. and E. N. conducted the research; E. P. and E. N. conducted the quality assessment of studies. S. K. analysed the data, S. K. and H. K.-B. drafted the manuscript; S. K., H. K.-B., E. P and E. N. finalised the paper. All the authors read and approved the final version of the manuscript.

The authors declare that they have no conflicts of interests regarding the publication of this article.

\section{Supplementary material}

For supplementary material/s referred to in this article, please visit http://dx.doi.org/doi:10.1017/S0007114515005012

\section{References}

1. Gaziano TA (2005) Cardiovascular disease in the developing world and its cost-effective management. Circulation 112, $3547-3553$

2. Imamura T, Doi Y, Arima H, et al. (2009) LDL cholesterol and the development of stroke subtypes and coronary heart disease in a general Japanese population: the Hisayama study. Stroke 40, 382-388.

3. Matsuura E, Hughes GR \& Khamashta MA (2008) Oxidation of LDL and its clinical implication. Autoimmun Rev 7, 558-566.

4. Young I \& Woodside J (2001) Antioxidants in health and disease. Am J Clin Pathol 54, 176-186.

5. Stocker R \& Keaney JF Jr (2004) Role of oxidative modifications in atherosclerosis. Physiol Rev 84, 1381-1478. 
6. Niki E (2011) Do free radicals play causal role in atherosclerosis? Low density lipoprotein oxidation and vitamin $\mathrm{E}$ revisited. J Clin Biochem Nutr 48, 3.

7. Mozaffarian D, Micha R \& Wallace S (2010) Effects on coronary heart disease of increasing polyunsaturated fat in place of saturated fat: a systematic review and meta-analysis of randomized controlled trials. PLoS Med 7, e1000252.

8. Kris-Etherton PM (1999) Monounsaturated fatty acids and risk of cardiovascular disease. Circulation 100, 1253-1258.

9. Namiki M (2007) Nutraceutical functions of sesame: a review. Crit Rev Food Sci Nutr 47, 651-673.

10. Sankar D, Rao MR, Sambandam G, et al. (2006aA pilot study of open label sesame oil in hypertensive diabetics. J Med Food $\mathbf{9}$, 408-412.

11. Matsumura Y (2004) The anti-hypertensive effect of sesamin. In Novel Compounds from Natural Products in the New Millennium: Potential and Challenges, p. 170 [BK-H Tan, B-H Bay and Y-Z Zhu, editors]. Singapore: World Science.

12. Kita S, Matsumura Y, Morimoto S, et al. (1995) Antihypertensive effect of sesamin. II. Protection against twokidney, one-clip renal hypertension and cardiovascular hypertrophy. Biol Pharm Bull 18, 1283-1285.

13. Wu W-H (2007) The contents of lignans in commercial sesame oils of Taiwan and their changes during heating. Food Chem 104, 341-344.

14. Moazzami AA \& Kamal-Eldin A (2006) Sesame seed is a rich source of dietary lignans. J Am Oil Chem Soc 83, 719-723.

15. Nakai M, Harada M, Nakahara K, et al. (2003) Novel antioxidative metabolites in rat liver with ingested sesamin.J Agric Food Chem 51, 1666-1670.

16. Lemcke-Norojärvi $\mathrm{M}$, Kamal-Eldin A, Appelqvist L-Å, et al. (2001) Corn and sesame oils increase serum $\gamma$-tocopherol concentrations in healthy Swedish women. J Nutr 131, $1195-1201$.

17. Hirose N, Inoue T, Nishihara K, et al. (1991) Inhibition of cholesterol absorption and synthesis in rats by sesamin. J Lipid Res 32, 629.

18. Sirato-Yasumoto S, Katsuta M, Okuyama Y, et al. (2001) Effect of sesame seeds rich in sesamin and sesamolin on fatty acid oxidation in rat liver. J Agric Food Chem 49, 2647-2651.

19. Ashakumary L, Rouyer I, Takahashi Y, et al. (1999) Sesamin, a sesame lignan, is a potent inducer of hepatic fatty acid oxidation in the rat. Metabolism 48, 1303-1313.

20. Dhar P, Chattopadhya K, Bhattacharyya D, et al. (2007) Ameliorative influence of sesame lignans on lipid profile and lipid peroxidation in induced diabetic rats. I Agric Food Chem 55, 5875-5880

21. Ramesh B, Saravanan R \& Pugalendi K (2005) Influence of sesame oil on blood glucose, lipid peroxidation, and antioxidant status in streptozotocin diabetic rats. J Med Food $\mathbf{8}$, 377-381.

22. Farajzadeh Sheikh A, Zahdei Asl S, Asgarisabzkoohi N, et al. (2006) The effects of ground sesame seeds (Ardeh) and sunflower oil on the serum lipid profile of the rats. Iran J Diabetes Lipid Disord 6, 45-50.

23. Wu JH, Hodgson JM, Puddey IB, et al. (2009) Sesame supplementation does not improve cardiovascular disease risk markers in overweight men and women. Nutr Metab Cardiovasc Dis 19, 774-780.

24. Sankar D, Rao MR, Sambandam G, et al. (2006bEffect of sesame oil on diuretics or Beta-blockers in the modulation of blood pressure, anthropometry, lipid profile, and redox status. Yale J Biol Med 79, 19-26.

25. Chen P-R, Tsai CE, Chang H, et al. (2005) Sesamol induces nitric oxide release from human umbilical vein endothelial cells. Lipids 40, 955-961.
26. Moher D, Liberati A, Tetzlaff J, et al. (2009) Preferred reporting items for systematic reviews and meta-analyses: the PRISMA statement. Ann Intern Med 151, 264-269.

27. van Rosendal SP, Osborne MA, Fassett RG, et al. (2010) Guidelines for glycerol use in hyperhydration and rehydration associated with exercise. Sports Med 40, 113-139.

28. Higgins JP \& Green S (2008) Cochrane Handbook for Systematic Reviews of Interventions, vol. 5. Chichester: Wiley Online Library.

29. DerSimonian R \& Laird N (1986) Meta-analysis in clinical trials. Control Clin Trials 7, 177-188.

30. Sankar D, Sambandam G, Rao MR, et al. (2005) Modulation of blood pressure, lipid profiles and redox status in hypertensive patients taking different edible oils. Clin Chim Acta 355, 97-104.

31. Wu JH, Hodgson JM, Puddey IB, et al. (2009) Sesame supplementation does not improve cardiovascular disease risk markers in overweight men and women. Nutr Metab Cardiovasc Dis 19, 774-780.

32. Helli B, Mowla K, Mohammadshahi M, et al. (2015) Effect of sesamin supplementation on cardiovascular risk factors in women with rheumatoid arthritis. J Am Coll Nutr (epublication ahead of print version 7 July 2015).

33. Wu WH, Kang YP, Wang NH, et al. (2006) Sesame ingestion affects sex hormones, antioxidant status, and blood lipids in postmenopausal women. J Nutr 136, 1270-1275.

34. Mirmiran P, Bahadoran Z, Golzarand M, et al. (2013) Ardeh (Sesamum indicum) could improve serum triglycerides and atherogenic lipid parameters in type 2 diabetic patients: a randomized clinical trial. Arch Iran Med 16, 652-656.

35. Lemcke-Norojärvi M, Kamal-Eldin A, Appelqvist LA, et al. (2001) Corn and sesame oils increase serum gamma-tocopherol concentrations in healthy Swedish women. J Nutr 131, $1195-1201$

36. Alipoor B, Haghighian MK, Sadat BE, et al. (2012) Effect of sesame seed on lipid profile and redox status in hyperlipidemic patients. Int J Food Sci Nutr 63, 674-678.

37. Khajehdehi P (2000) Lipid-lowering effect of polyunsaturated fatty acids in hemodialysis patients. J Ren Nutr 10, 191-195.

38. Miyawaki T, Aono H, Toyoda-Ono Y, et al. (2009) Antihypertensive effects of sesamin in humans. J Nutr Sci Vitaminol 55, 87-91.

39. Nordestgaard BG \& Varbo A (2014) Triglycerides and cardiovascular disease. Lancet 384, 626-635.

40. Catapano AL, Farnier M, Foody JM, et al. (2014) Combination therapy in dyslipidemia: where are we now? Atherosclerosis 237, 319-335.

41. Banach M (2015) Combination Therapy in Dyslipidemia. Basel, Switzerland: Springer.

42. Banach M, Rizzo M, Toth PP, et al. (2015) Statin intolerance an attempt at a unified definition. Position paper from an International Lipid Expert Panel. Arch Med Sci 11, 1-23.

43. Tsuruoka N, Kidokoro A, Matsumoto I, et al. (2005) Modulating effect of sesamin, a functional lignan in sesame seeds, on the transcription levels of lipid- and alcohol-metabolizing enzymes in rat liver: a DNA microarray study. Biosci Biotechnol Biochem 69, 179.

44. Nakai M, Harada M, Nakahara K, et al. (2003) Novel antioxidative metabolites in rat liver with ingested sesamin. J Agric Food Chem 51, 1666-1670.

45. Schwingshackl L \& Hoffmann G (2012) Monounsaturated fatty acids and risk of cardiovascular disease: synopsis of the evidence available from systematic reviews and meta-analyses. Nutrients 4, 1989-2007.

46. Harris WS, Mozaffarian D, Rimm E, et al. (2009) Omega-6 fatty acids and risk for cardiovascular disease: a science advisory from the American Heart Association Nutrition Subcommittee of the Council on Nutrition, Physical Activity, and Metabolism; 
Council on Cardiovascular Nursing; and Council on Epidemiology and Prevention. Circulation 119, 902-907.

47. Zhu Q, Huang Y \& Chen Z (2000) Interaction between flavonoids and alpha-tocopherol in human low density lipoprotein. J Nutr Biochem 11, 14-21.

48. Hemalatha S \& Rao M (2004) Sesame lignans enhance antioxidant activity of vitamin $\mathrm{E}$ in lipid peroxidation systems. Mol Cell Biochem 262, 195-202.

49. Kamal-Eldin A, Frank J, Razdan A, et al. (2000) Effects of dietary phenolic compounds on tocopherol, cholesterol, and fatty acids in rats. Lipids 35, 427-435.

50. Yamashita K, Iizuka Y, Imai T, et al. (1995) Sesame seed and its lignans produce marked enhancement of vitamin $\mathrm{E}$ activity in rats fed a low alpha-tocopherol diet. Lipids 30, 1019-1028.

51. Kang M-H, Katsuzaki H \& Osawa T (1998) Inhibition of 2, 2 '-azobis (2,4-dimethylvaleronitrile)-induced lipid peroxidation by sesaminols. Lipids 33, 1031-1036.

52. Kang M-H, Naito M, Sakai K, et al. (1999) Mode of action of sesame lignans in protecting lowdensity lipoprotein against oxidative damage in vitro. Life Sci 66, 161-171.
53. Steinbrecher U, Parthasarathy S, Leake D, et al. (1984) Modification of low density lipoprotein by endothelial cells involves lipid peroxidation and degradation of low density lipoprotein phospholipids. Proc Natl Acad Sci U S A 81, 3883-3887.

54. Ide T, Ashakumary L, Takahashi Y, et al. (2001) Sesamin, a sesame lignan, decreases fatty acid synthesis in rat liver accompanying the down-regulation of sterol regulatory element binding protein-1. Biochim Biophys Acta 1534, $1-13$.

55. Umeda-Sawada R, Ogawa M, Nakamura M, et al. (2001) Effect of sesamin on mitochondrial and peroxisomal beta-oxidation of arachidonic and eicosapentaenoic acids in rat liver. Lipids 36, 483-489.

56. Desvergne B \& Wahli W (1999) Peroxisome proliferatoractivated receptors: nuclear control of metabolism. Endocr Rev 20, 649-688.

57. Sankar D, Ali A, Sambandam G, et al. (2011) Sesame oil exhibits synergistic effect with anti-diabetic medication in patients with type 2 diabetes mellitus. Clin Nutr 30, 351-358. 